Bull. Chem. Soc. Ethiop. 2019, 33(1), 43-50.

ISSN 1011-3924

(C) 2019 Chemical Society of Ethiopia and The Authors

Printed in Ethiopia

DOI: https://dx.doi.org/10.4314/bcse.v33i1.4

\title{
APPLICATION OF A WATER STABLE ZINC(II) GLUTAMATE METAL ORGANIC FRAMEWORK FOR PHOTOCATALYTIC DEGRADATION OF ORGANIC DYES
}

\author{
Wei-Ping $\mathrm{Wu}^{1 *}$, Wei-Cong Liu ${ }^{2}$, Shuo-Wen Qiu ${ }^{2}$, Ai-Qing Ma ${ }^{2 *}$, Wei Dai ${ }^{2}$, Yu Qian ${ }^{2}$ and \\ Abhinav Kumar ${ }^{3 *}$ \\ ${ }^{1}$ College of Chemistry and Environmental Engineering, Sichuan University of Science \& \\ Engineering, Zigong 643000, P. R. China \\ ${ }^{2}$ Dongguan Key Laboratory of Drug Design and Formulation Technology, Key Laboratory of \\ Research and Development of New Medical Materials of Guangdong Medical University, \\ School of Pharmacy, Guangdong Medical University, Dongguan, 523808, P. R. China \\ ${ }^{3}$ Department of Chemistry, Faculty of Science, University of Lucknow, Lucknow 226007 , India
}

(Received April 12, 2018; Revised September 1, 2018; Accepted December 24, 2018)

\begin{abstract}
A water stable metal-organic framework (MOF) having structural formula $\left\{\left[\mathrm{Zn}\left(\mathrm{H}_{2} \mathrm{O}\right)(\mathrm{L})\right] \cdot x \text { solvent }\right\}_{\mathrm{n}}(\mathrm{L}=$ glutamate) (1), was prepared in aqueous medium by simple mixing the $\mathrm{Zn}$ (II) salt and glutamate ligand at room temperature. The single crystal X-ray diffraction study indicates that 1 crystallizes in an orthorhombic system with a space group of $P 2{ }_{1}{ }_{1}{ }_{1} 2_{1}$ in which the $\mathrm{Zn}$ (II) center adopts pseudo-octahedral geometry. The bridging interactions through carboxylate groups in $\mathbf{1}$ generates a 2D structure in 1 comprising of the microporous channels. The UV/Vis diffuse-reflection spectroscopy for $\mathbf{1}$ had been performed which indicated that MOF possess semiconducting nature with a band gap of $3.23 \mathrm{eV}$ and therefore may be a potential candidate as photocatalyst. The photocatalytic behavior of 1 against photo-degratdation of organic dyes has been investigated. The possible photocatalytic activity of 1 against organic dyes have been addressed using density of states (DOS) calculations.
\end{abstract}

KEY WORDS: Glutamate, MOF, DOS, Photocatalysis

\section{INTRODUCTION}

During the last few years the metal-organic frameworks (MOFs) have received extensive attention as they find applications as a promising photocatalyst in decomposing organic dyes owing to their high specific surface area and high light absorption abilities [1-4]. The wellknown MOF-5 for phenol degradation under UV light irradiation have already been demonstrated to have semiconducting properties for photo-electronics and photocatalysis [5], lately, a 2-fold interpenetrated porous MOF $\left[\mathrm{Zn}_{4} \mathrm{O}(2,6-\mathrm{ndc})_{3}(\mathrm{DMF})_{1.5}\left(\mathrm{H}_{2} \mathrm{O}\right)_{0.5}\right] \cdot 4 \mathrm{DMF} \cdot 7.5 \mathrm{H}_{2} \mathrm{O}$ $\left(\mathrm{H}_{2} 2,6\right.$-ndc $=2,6^{\prime}$ - naphthalenedicarboxylic acid) (UTSA-38) had been used for the degradation of methyl orange (MO) in aqueous solution under UV [6]. A UiO-66( $\left.\mathrm{NH}_{2}\right)$ MOF has also shown visible-light-responsive photocatalytic activity toward the degradation of organic dyes [7]. Until now, some few reviews have been published which encompasses the applications of MOFs in the area of photocatalysis and artificial photosynthesis [8-10].

Generally, MOFs used to degrade dyes are having porous morphology with $2 \mathrm{D}$ or $3 \mathrm{D}$ frameworks [11]. The stability and recyclability of these MOFs requires improvement. Therefore, it is important to synthesize stable MOFs that can be used for degradation of organic dyes. In particular, the selection of the ligand plays a crucial role in designing as well as construction of the stable MOFs [12-13]. With these viewpoints and in our continuous pursuit for the development of new MOFs for the organic dye-degradation in the waste-water discharge. Herein, a water stable zinc-glutamate-MOF having the structural formula

*Corresponding author. E-mail: wuweipingzg@126.com, maqandght@126.com and abhinavmarshal@gmail.com

This work is licensed under the Creative Commons Attribution 4.0 International License 
$\left\{\left[\mathrm{Zn}\left(\mathrm{H}_{2} \mathrm{O}\right)(\mathrm{L})\right] \cdot x \text { solvent }\right\}_{\mathrm{n}}(\mathrm{L}=$ glutamate $)(\mathbf{1})$, had been chosen which was prepared instantly in aqueous medium by simple mixing the reactants at room temperature had been used as the possible photocatalyst for the degradation of organic dyes and the probable mechanism of the photocatalysis have been addressed using density of states (DOS) calculations. Additionally, the $\mathrm{UV} / \mathrm{V}$ is diffuse-reflection spectra have also been investigated.

\section{EXPERIMENTAL}

\section{General considerations}

All the purchased chemicals were used without further purification. Powder X-ray diffraction (PXRD) data was collected on Bruker D8 ADVANCE X-ray diffractometer with $\mathrm{Cu}-\mathrm{K} \alpha$ radiation $(\lambda=1.5418 \AA)$ at $50 \mathrm{kV}, 20 \mathrm{~mA}$ with a scanning rate of $6 \% \mathrm{~min}$ and a step size of $0.02^{\circ}$. The simulated powder patterns were calculated using Mercury 2.0. The purity and homogeneity of the bulk products were determined by comparing the simulated and experimental X-ray powder diffraction patterns. Fourier transform infrared (FT-IR) spectra as $\mathrm{KBr}$ pellet were measured using a Nicolet Impact $750 \mathrm{FTIR}$ in the range of $400-4000 \mathrm{~cm}^{-1}$. We followed the photocatalytic method and computational details from our current work [14].

Synthesis of $\left\{\left[\mathrm{Zn}\left(\mathrm{H}_{2} \mathrm{O}\right)(L)\right] \cdot \operatorname{xsolvent}_{n}(\mathbf{1})\right.$

The synthesis procedure of 1 was analogous to previous work [14], except that volume of $\mathrm{H}_{2} \mathrm{O}$ in our synthesis was increased to 1.5 times.

\section{Photocatalytic reactions}

The experiment was carried out in a typical process. $1(0.062 \mathrm{~g})$ was added into $200 \mathrm{~mL}$ of methyl violet $(\mathrm{MV})$ and rhodamine-B $(\mathrm{RhB})\left(10 \mathrm{mg} \mathrm{L}^{-1}\right)$. The suspension solution was stirred in the dark for about $30 \mathrm{~min}$. Then, the mixture was stirred continuously under UV irradiation from a $175 \mathrm{~W}$ pressure mercury vapor lamp (main output $365 \mathrm{~nm}$ ). At a given interval, aliquots of the reaction mixture were periodically taken and analyzed using a UV-vis spectrophotometer. This procedure was repeated in the absence of a catalyst as a blank comparison experiment.

\section{Computational details}

The probable mechanism of the photocatalysis of organic dyes in presence of $\mathbf{1}$ has been addressed using density of states (DOS) calculations. The geometry optimization of the $\mathbf{1}$ have been done using B3LYP functional and using 6-31G** basis set for all the atoms. All the calculations were performed using Gaussian 09 program [15] and GaussSum 3.1 was used to obtain density of state (DOS) plots [16].

\section{RESULTS AND DISCUSSION}

Structure description of $\left\{\left[\mathrm{Zn}\left(\mathrm{H}_{2} \mathrm{O}\right)(\mathrm{L})\right] \cdot \operatorname{xsolvent}_{n}(\mathbf{1})\right.$

Single crystal X-ray diffraction analysis reveals that $\mathbf{1}$ crystallizes in an orthorhombic system with a space group of $P 2{ }_{1}{ }_{1} 2_{1}$. The title compound has been firstly reported by Kempe et al. [17]. The asymmetric unit comprises of crystallagraphically unique $\mathrm{Zn}$ (II) ion, a coordinated water molecule and a L ligand. The $\mathrm{Zn}(1)$ is pseudo-octahedrally coordinated by one nitrogen atom (N1) from amino group and one oxygen atom (O3) bridging carboxyl group at the axial position, two oxygen atoms (O2 and $\mathrm{O} 5)$ from bridging carboxyl group and chelating carboxyl 
group and one oxygen atom (O4) from a coordinated water molecule making up the basal plane (Figure 1a) [14,16-18]. The bridging interactions are responsible for organization of the metal atoms into a 2D structure (Figure 1b) with microporous channels.
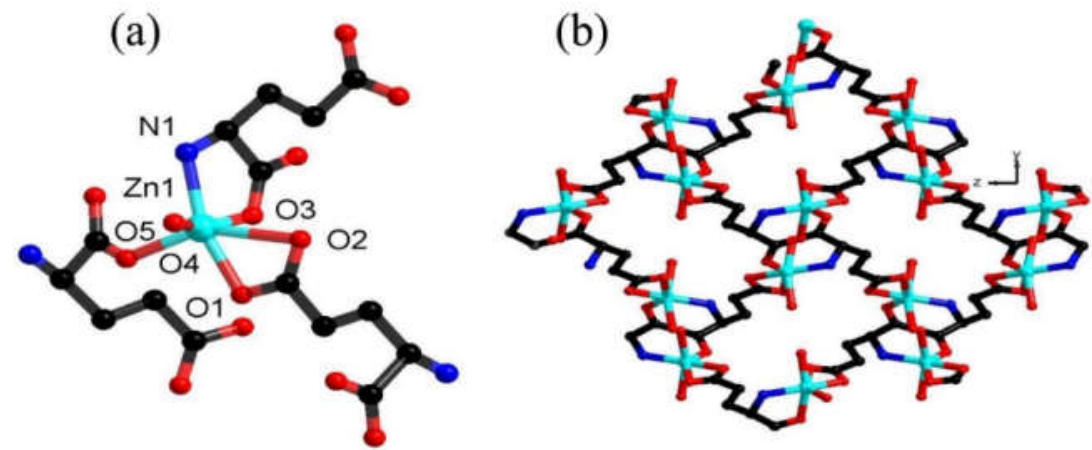

Figure 1. (a) view of the local coordination geometry of metal center; (b) view of layer packing diagram along the $b c$-plane.

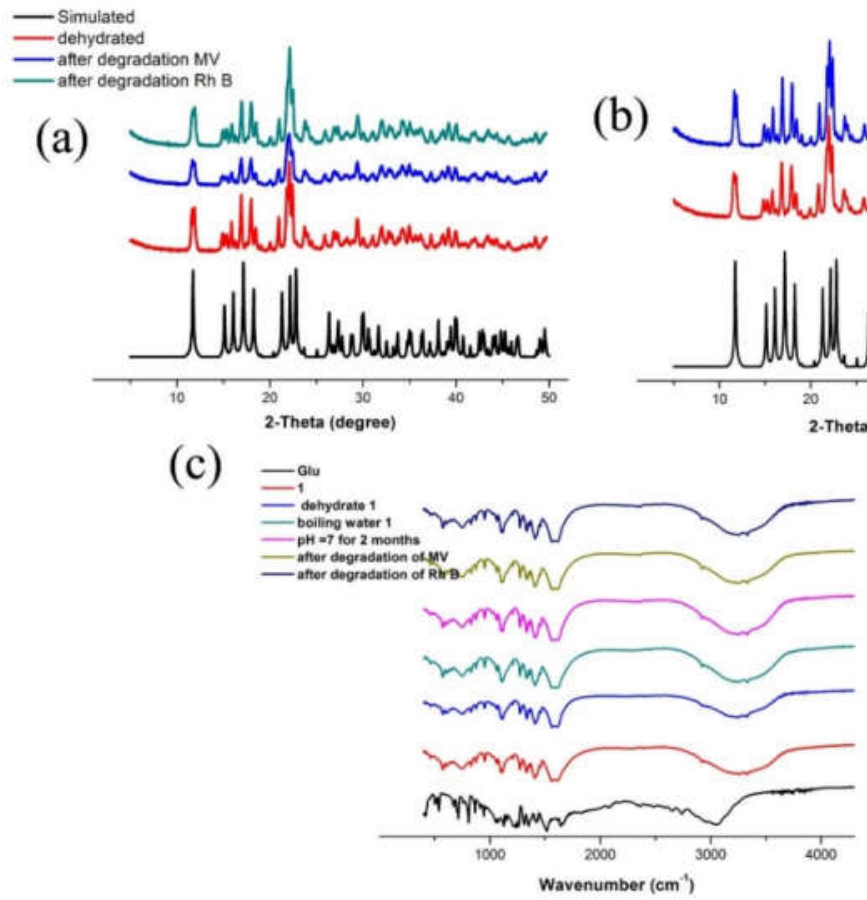

Figure 2. Powder XRD profiles of 1 (a) as-synthesized samples, dehydrated samples and after being used as photocatalyst to photo-degrade dyes; (b) soaked in water medium for different time length; (c) IR spectra of 1 at different medium and conditions. 
The PXRD patterns and FTIR spectra revealed that the single crystal and the rapidly synthesized 1 were similar with previous ones (Figure 2a and Figure 2c) [16-18]. The single crystals of 1 remain unchanged in air for a very long time. Powder X-ray diffraction (XRD) patterns have unambiguously demonstrated that the crystallinity and framework integrity of 1 can be well retained even when 1 was kept in boiling water for $12 \mathrm{~h}$ (Figure 2b). Also, 1 also remains unchanged in water for a period of 2 months (Figure $2 b$ ). The exceptional stability of 1 can be attributed to the strong $\mathrm{Zn}-\mathrm{N}$ bond. Undoubtedly, the pronounced stability of $\mathbf{1}$ build a nice foundation for its further application.

\section{Diffuse-reflectance UV/Vis spectroscopy}

The solid state UV-vis absorption spectrum of $\mathbf{1}$ is presented in Figure 3 which display a band with maxima at $c a$. $325 \mathrm{~nm}$, which can be attributed to $\pi-\pi^{*}$ transitions of the ligand or ligandto-metal charge transfer [19-20]. The absorption $(\alpha / \mathrm{S})$ data were calculated from the reflectance using the Kubelka-Munk function: $\alpha / S=(1-R)^{2} / 2 R$, where $\alpha$ is the absorption, $S$ is the scattering coefficient, and $\mathrm{R}$ is the reflectance at a given energy. The energy band gap $\left(E_{\mathrm{g}}\right)$ was obtained by extrapolation of the linear portion of the absorption edges and the estimated value comes to be $3.23 \mathrm{eV}$ thereby indicating semiconducting nature of $\mathbf{1}$. The band gap magnitude of 1 indicated that it may possess the potentials as semiconductor materials and may find applications as photocatalyst in photocatalytic reactions [21-23].
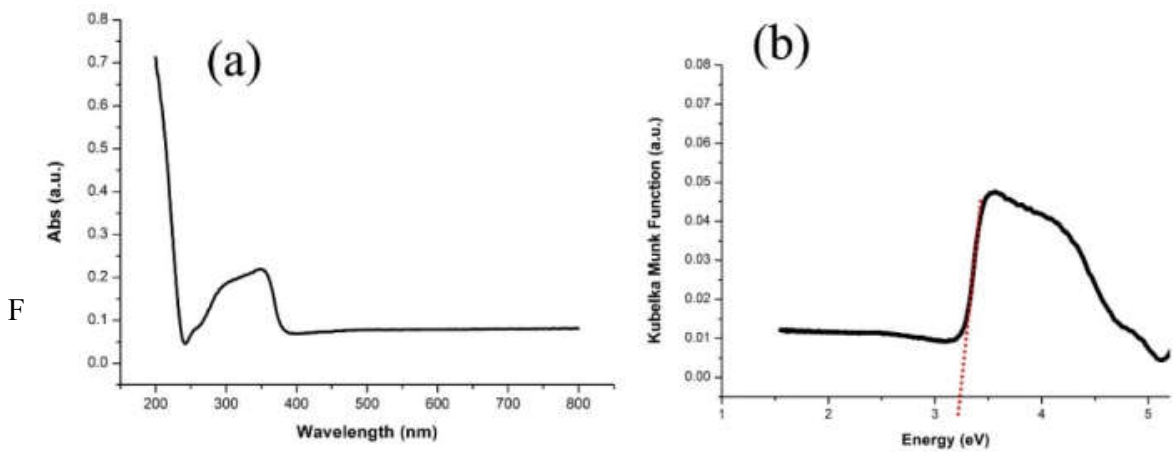

Figure 3. (a) UV-vis diffuse-reflectance spectra of 1. (b) Solid-state optical diffuse-reflection spectra of 1 derived from diffuse reflectance data at ambient temperature. The intercept of the extrapolated absorption edge on the energy scale ( $\mathrm{x}$ axis) gives the band gap of the samples.

\section{Photocatalysis}

The photocatalytic activities of 1 was evaluated by using the MOF as photocatalyst in the photodegradation of $\mathrm{MV} / \mathrm{RhB}$ dyes $\left(0.032 \mathrm{~g} \mathrm{~L}^{-1}\right)$ in water and irradiating the samples under a $250 \mathrm{~W}$ $\mathrm{Hg}$ lamp. The degradation ratios of $\mathrm{MV} / \mathrm{RhB}$ dyes in water were monitored by observing the intensity of the characteristic absorption band of MV/RhB dyes (Figure 4a-b). The UV-Vis spectroscopy indicated that no new absorption band appeared in the UV-vis absorption spectrum thereby indicating the complete decomposition of $\mathrm{MV} / \mathrm{RhB}$ dyes in water. The calculation results show that the conversion rates of $\mathrm{MV}$ and $\mathrm{RhB}$ are $73.3 \%$ and $55.1 \%$, respectively. For the sake of comparison, the total catalytic degradation efficiency of the control experiment (without the use of catalyst 1) had also been carried out. The degradation rates of MV and RhB were merely $10.8 \%$ and $15.6 \%$, respectively within 100 min under the same 
condition. The absorbance of MB without any catalysis under UV irradiation decreased in the beginning, but the rate of decomposition became slow later time. This observation is consistent with the previous reports [24-26]. The current results indicated that UV-vis light may induce the $\mathrm{MOF}$ /organic ligands (L) to produce $\mathrm{O} / \mathrm{N}$-metal charge transfer by promoting an electron from the highest occupied molecular orbital (HOMO) to the lowest unoccupied molecular orbital (LUMO). The charge transfer excited state (MOFs/or L*) can be deactivated by oxidizing the contaminant directly and/or oxygenating water molecules into ${ }^{\circ} \mathrm{OH}$ radicals to complete the photocatalytic process [25].
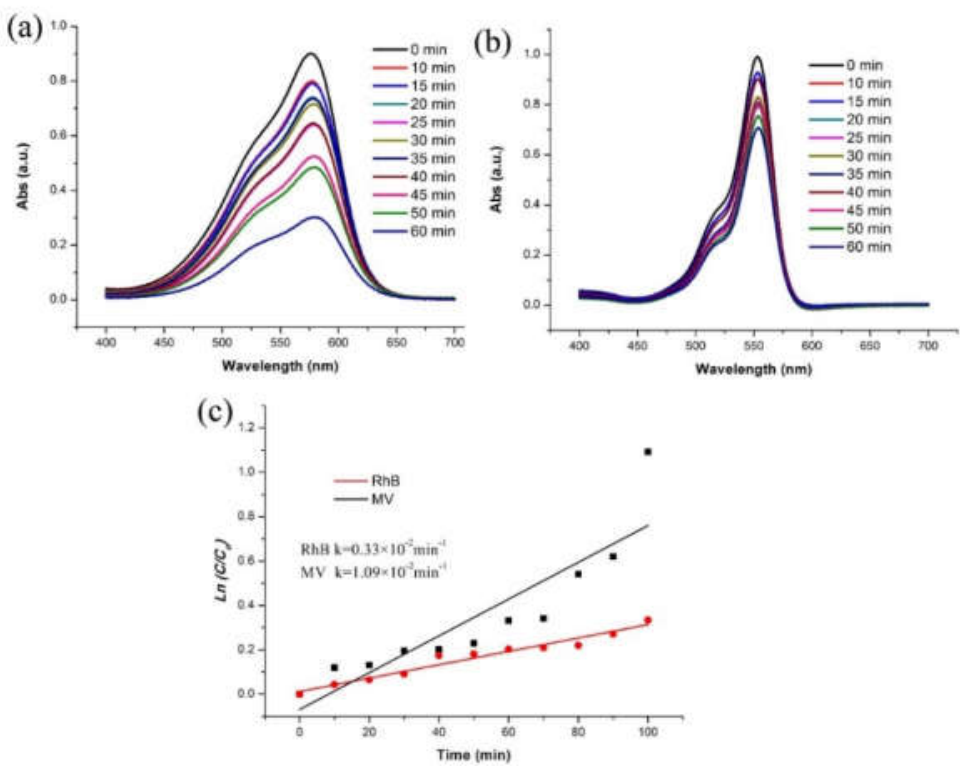

Figure 4. (a) and (b) UV-vis absorption spectra of the MV and RhB solution during the decomposition reaction under $250 \mathrm{~W} \mathrm{Hg}$ lamp irradiation in the presence of $\mathbf{1}$, respectively; (c) the plot displaying photocatalytic degradation kinetics of $\mathrm{MV} / \mathrm{RhB}$ with different concentration of $\mathbf{1}$.

In addition, the photo-stability of $\mathbf{1}$ was monitored using PXRD analysis during the course of the photocatalytic reactions (Figure 2a), which indicated that there was no appreciable morphological changes in the MOF. Also, 1 can be reused for three catalytic cycles without significant photocatalytic efficiency decay and obvious loss of crystallinity (Figure 1a). From these result we infer that $\mathbf{1}$ can be a robust catalyst for MV and RhB photodegradation.

To investigate the kinetics of $\mathrm{MV} / \mathrm{RhB}$ photocatalytic degradation by $\mathbf{1}$, experimental data can be described by using the well-known Langmuir-Hinshelwood model as expressed by $\ln \left(C / C_{0}\right)=-k t$ ( $k=$ apparent reaction rate constant) (Figure $\left.4 \mathrm{c}\right) . C_{0}$ is the initial concentration of $\mathrm{MV} / \mathrm{RhB}, \mathrm{t}$ is the reaction time, and $C$ is the concentration of $\mathrm{RhB} / \mathrm{MV}$ at the reaction time $\mathrm{t}$. The plot of $\ln \left(C_{0} / C\right)$ and irradiation time $(\mathrm{t})$ is approximately linear and approximated the firstorder kinetic equation (Figure 4c). The calculated apparent rate constant $(k)$ for the photodegradation of $\mathrm{Rh} \mathrm{B}$ and $\mathrm{MV}$ in the presence of 1 are $0.33 \times 10^{-2}$ and $1.09 \times 10^{-2} \mathrm{~min}^{-1}$, respectively. Thus, 1 could be an efficient photo-catalyst for degrading MV in comparison to RhB [27-29]. 
The most likely photocatalytic degradation mechanism of organic dyes in the presence of $\mathbf{1}$ has been addressed with the aid of band structure calculations on $\mathbf{1}$ which is based on DFT method [30-31]. As presented in Figure 5, the valence band lying just below the Fermi level of 1 is mainly contributed by the carboxylate oxygen of the glutamate moiety with meager contribution coming from $\mathrm{Zn}(\mathrm{II})$, coordinated nitrogen and carbon centers. Also, the conduction band lying just above the Fermi level in the range of 1.46 to $2.10 \mathrm{eV}$ has been derived from carbon center with slight admixture from the oxygen centers. Therefore, the electronic transition in 1 mainly takes place from the carboxylate oxygen with meagre contributions from the $\mathrm{Zn}$ (II), nitrogen center to carbon center. In the typical photocatalytic process, the sample 1 can be excited to produce electron-hole pairs under visible light irradiation and as band structure calculations reveal that the hole moves to $\mathrm{Zn}$ (II) centers and the electron migrates to glutamate entity. The generation of holes on the $\mathrm{Zn}$ (II) centers will correspond to its oxidation which is now capable to oxidize the dye to re-reduce back to $\mathrm{Zn}(\mathrm{II})$ again.

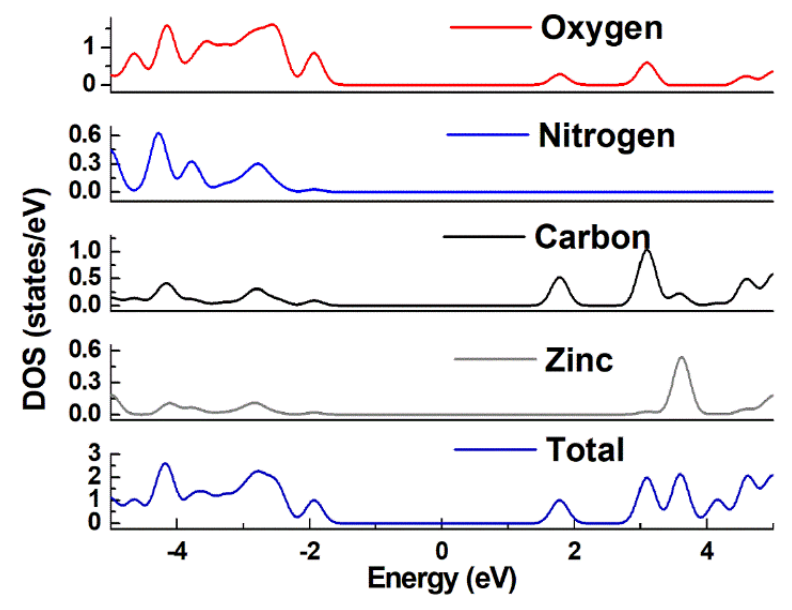

Figure 5. Density of states (DOS) and partial DOS for $\mathbf{1 .}$

\section{CONCLUSION}

The water stable zinc(II)-based MOF showed semiconducting nature with a band gap of $3.23 \mathrm{eV}$ as evidenced by the UV/Vis diffuse-reflection spectroscopy and hence used as photocatalyst for the photo-degradation of methyl violet and Rhodamine B dyes. The DOS calculations reveals that under irradiation of $\mathbf{1}$ the hole moves to $\mathrm{Zn}$ (II) centers and the electron migrates to carbon centers. The generation of holes on the $\mathrm{Zn}$ (II) centers will correspond to its oxidation which is now capable to oxidize the dye to re-reduce back to $\mathrm{Zn}$ (II) again. Such types of MOFs prove to be a good catalyst for organic dyes and definitely such systems will be worthy to develop new and versatile materials photocatalyts.

\section{ACKNOWLEDGMENTS}

This work was partially supported by the grants from NSF of China (21701033), Science Foundation funded project of Guangdong Medical University (Z2016001 and M2016023), the Public Research and Capacity Building Projects of Department of Guangdong Province (2017A010103022), Natural Science Foundation of Guangdong Province (2017A030313079), 
Innovative Entrepreneurial Training Plan of undergraduates in Guangdong Province (201710571012; 201710571019, 201710571060, 201710571008, 201710571016).

\section{REFERENCES}

1. Wang, F.Q.; Wang, C.M.; Yu, Z.C.; He, Q.G.; Li, X.Y.; Shang, C.L.; Zhao, Y.N. Two luminescent metal-organic frameworks with multifunctional properties for nitroaromatic compounds sensing and photocatalysis. RSC Adv. 2015, 5, 70086-70093.

2. Huang, Y.B.; Liang, J.; Wang, X.S.; Cao, R. Multifunctional metal-organic framework catalysts: Synergistic catalysis and tandem reactions. Chem. Soc. Rev. 2017, 46, 126-157..

3. Martin, D.J.; Liu, G.; Moniz, S.J.A.; Bi, Y.; Beale, A.M.; Ye, J.; Tang, J. Efficient visible driven photocatalyst, silver phosphate: Performance, understanding and perspective. Chem. Soc. Rev. 2015, 44, 7808-7828.

4. Wang, S.B.; Wang, X.C. Multifunctional metal-organic frameworks for photocatalysis. Small 2015, 11, 3097-3112.

5. Llabrés i Xamena, F.X.; Corma, A.; Garcia, H. Applications for metal-organic frameworks (MOFs) as quantum dot semiconductors. J. Phys. Chem. C, 2007, 111, 80-85.

6. Das, M.C.; Xu, H.; Wang, Z.; Srinivas, G.; Zhou, W.; Yue, Y.F.; Nesterov, V.N.; Qian, G.; Chen, B. A Zn 4 O-containing doubly interpenetrated porous metal-organic framework for photocatalytic decomposition of methyl orange. Chem. Commun. 2011, 47, 11715-11717.

7. Shen, L.; Wu, W.; Liang, R.; Lin, R.; Wu, L. Highly dispersed palladium nanoparticles anchored on UiO-66 $\left(\mathrm{NH}_{2}\right)$ metal-organic framework as a reusable and dual functional visible-light-driven photocatalyst. Nanoscale, 2013, 5, 9374-9382.

8. Li, S.L.; Xu, Q. Metal-organic frameworks as platforms for clean energy. Energy Environ. Sci. 2013, 6, 1656-1683.

9. Zhang, T.; Lin, W. Metal-organic frameworks for artificial photosynthesis and photocatalysis. Chem. Soc. Rev. 2014, 43, 5982-5993.

10. Wang, C.C.; Zhang, Y.Q.; Li, J.; Wang, P. Photocatalytic $\mathrm{CO}_{2}$ reduction in metal-organic frameworks: a mini review. J. Mol. Struct. 2015, 1083,127-136.

11. Zhang, S.R.; Du, D.Y.; Qin, J.S.; Bao, S.J.; Li, S.L.; He, W.W.; Lan, Y.Q.; Shen, P.; Su, Z.M. A fluorescent sensor for highly selective detection of nitroaromatic explosives based on a 2D, extremely stable, metal-organic framework. Chem. Eur. J. 2014, 20, 3589-3594.

12. Sella, E. Shabat, D. Self-immolative dendritic probe for direct detection of triacetone triperoxide. Chem. Commun. 2008, 110, 5701-5703.

13. Jin, J.C.; Wu, J.; He, Y.X.; Li, B.H.; Liu, J.Q.; Prasad, R.; Kumar, A.; Batten, S.R. A 3D luminescent $\mathrm{Zn}(\mathrm{II}) \mathrm{MOF}$ for the detection of high explosives and the degradation of organic dyes: An experimental and computational study. CrystEngComm 2017, 19, 6464-6472.

14. Kathalikkattil, A.C.; Roshan, R.; Tharun, J.; Babu, R.; Jeong, G.S.; Kim, D.W.; Choc, S.J. Park, D.W. A sustainable protocol for the facile synthesis of zinc-glutamate MOF: An efficient catalyst for room temperature $\mathrm{CO}_{2}$ fixation reactions under wet conditions. Chem. Commun. 2016, 52, 280-283.

15. Frisch, M.J.; Trucks, G.W.; Schlegel, H.B.; Scuseria, G.E.; Robb, M.A.; Cheeseman, J.R.; Montgomery, Vreven Jr., J.A.T.; Kudin, K.N.; Burant, J.C.; Millam, J.M.; Iyengar, S.S.; Tomasi, J.; Barone, V.; Mennucci, B.; Cossi, M.; Scalmani, G.; Rega, N.; Petersson, G. A.; Nakatsuji, H.; Hada, M.; Ehara, M.; Toyota, K.; Fukuda, R.; Hasegawa, J.; Ishida, M.; Nakajima, T.; Honda, Y.; Kitao, O.; Nakai, H.; Klene, M.; Li, X.; Knox, J.E.; Hratchian, H.P.; Cross, J.B.; Bakken, V.; Adamo, C.; Jaramillo, J.; Gomperts, R.; Stratmann, R.E.; Yazyev, O.; Austin, A.J.; Cammi, R.; Pomelli, C.; Ochterski, J.W.; Ayala, P.Y.; Morokuma, K.; Voth, G.A.; Salvador, P.; Dannenberg, J.J.; Zakrzewski, V.G.; Dapprich, S.; Daniels, A.D.; Strain, M.C.; Farkas, O.; Malick, D.K.; Rabuck, A.D.; Raghavachari, K.; Foresman, J.B.; Ortiz, J.V.; Cui, Q.; Baboul, A.G.; Clifford, Cioslowski, S. J.; Stefanov, B.B.; Liu, G.; 
Liashenko, A.; Piskorz, P.; Komaromi, I.; Martin, R.L.; Fox, D.J.; Keith, T.; Al-Laham, M.A.; Peng, C.Y.; Nanayakkara, A.; Challacombe, M.; Gill, P.M.W.; Johnson, B.; Chen, W.; Wong, W.M.; Gonzalez, C.; Pople, J.A. Gaussian, Inc.: Wallingford CT; 2009.

16. O'Boyle, N.M.; Tenderholt, A.L.; Langner, K.M. Cclib: A library for package - independent computational chemistry algorithms. J. Comp. Chem. 2008, 29, 839-845.

17. Proch, S.; Villanueva, J.M.R.; Irrgang, T.; Döring, C.; Kempe, R.; Kristallogr, Z. Refinement of the crystal structure of aquazinc(II) glutamate hydrate, $\mathrm{Zn}\left(\mathrm{H}_{2} \mathrm{O}\right)\left(\mathrm{C}_{5} \mathrm{H}_{7} \mathrm{NO}_{4}\right)$. $\mathrm{H}_{2} \mathrm{O}$. New Cryst. Struct. 2008, 223, 55-56.

18. Gramaccioli, C.M. The crystal structure of zinc glutamate dehydrate. Acta Crystallogr. 1966, 21, 600-605.

19. Sun, Q.; Lu, J.; Li, J.L.; Jiang, L.; Gu, W.; Liu, X.; Tian, J.L.; Yan, S.P. Synthesis, crystal structures, DNA binding and cleavage properties and protein binding activities of three mononuclear cobalt(II) complexes. Appl. Organomet. Chem. 2014, 28, 259-266.

20. Xiong, W.W.; Athersh, E.U.; Ng, Y.T.; Ding, J.F.; Wu, T.; Zhang, Q.C. Growing crystalline chalcogenidoarsenates in surfactants: From zero-dimensional cluster to three-dimensional framework. J. Am. Chem. Soc. 2013, 135, 1256-1259.

21. Hu, J.M.; Guo, R.; Liu,Y.G.; Cui, G.H. Four Co(II) coordination polymers based on 4,4'bis(benzimidazol-1-ylmethyl)biphenyl and aromatic carboxylic acids co-ligands: Synthesis, structures, and photocatalytic properties. Inorg. Chim. Acta 2016, 450, 418-425.

22. Qi, H.X.; Wang, J.F.; Ren, Z.G.; Ning, J.J.; Lang, J.P. Syntheses and structures of two gold(I) coordination compounds derived from $\mathrm{P}-\mathrm{S}$ hybrid ligands and their efficient catalytic performance in the photodegradation of nitroaromatics in water. Dalton Trans. 2015, 44, 5662-5671.

23. Cheng, H.J.; Tang, H.X.; Shen, Y.L.; Xia, N.N.; Yin, W.Y.; Zhu, W.; Tang, X.Y.; Ma, Y.S.; Yuan, R.X. Carboxylate ligands induced structural diversity of zinc(II) coordination polymers based on 3,6-bis(imidazol-1-yl)carbazole: Syntheses, structures and photocatalytic properties. J. Solid State Chem. 2015, 232, 200-206.

24. Dai, M.; Su, X.R.; Wang, X.; Wu, B.; Ren, Z.G.; Zhou, X.; Lang, J.P. Three zinc(II) Coordination polymers based on tetrakis(4-pyridyl)cyclobutane and naphthalenedicarboxylate linkers: Solvothermal syntheses, structures, and photocatalytic properties. Cryst. Growth Des. 2014, 14, 240-248.

25. Peng, Y.F.; Zhao, S.; Li, K.; Liu, L.; Li, B.H.; Wu, B. Construction of Cu(II), Z(II) and $\mathrm{Cd}(\mathrm{II})$ meta-organic frameworks of bis(1,2,4-triazol-4-yl)ethane and benzenetricarboxylate: Syntheses, structures and photocatalytic properties, CrystEngComm 2015, 17, 2544-2552.

26. Wang, F.; Li, F.L.; Xu, M.M.; Yu, H.; Zhang, J.G.; Xia, H.T.; Lang, J.P. Facile synthesis of a $\mathrm{Ag}(\mathrm{I})$-doped coordination polymer with enhanced catalytic performance in the photodegradation of azo dyes in water. J. Mater. Chem. A 2015, 3, 5908-5916.

27. Takeda, H.; Koike, K.; Inoue, H.; Ishitani, O. Development of an efficient photocatalytic system for $\mathrm{CO}_{2}$ reduction using rhenium(I) complexes based on mechanistic studies. J. Am. Chem. Soc. 2008, 130, 2023-2031.

28. Wang, J.L.; Wang, C.; Lin, W.B. Metal-organic frameworks for light harvesting and photocatalysis. ACS Catal. 2012, 2, 2630-2640.

29. Dey, D.; Kaur, G.; Patra, M.; Choudhury, A.R.; Kole, N.; Biswas, B. A perfectly linear trinuclear zinc-Schiff base complex: Synthesis, luminescence property and photocatalytic activity of zinc oxide nanoparticle. Inorg. Chim. Acta. 2014, 421, 335-341.

30. Lu, L.; Wang, J.; Wu, W.P.; Wu, X.R.; Kumar, A. Surface analysis and magnetism of a 1D Mn(II) complex. Bull. Chem. Soc. Ethiop. 2016, 30, 111-118

31. Zhou, E.H,; Wang, R.; Wu, J.; Qiu, S.W.; Liu, J.Q.; Zhong, H.R.; Zeng, H.D.; Xu, J.W.; Jin, J.C. A 3D polyhedral metal-organic framework as drug carrier for controllable release. Bull. Chem. Soc. Ethiop. 2017, 31, 457-463. 